\title{
Stress and Moisture Effects on Thin Film Buckling Delamination
}

\author{
P. Waters • A.A. Volinsky
}

Received: 25 December 2005 / Accepted: 25 May 2006 / Published online: 25 July 2006

(C) Society for Experimental Mechanics 2006

\begin{abstract}
Deposition processes control the properties of thin films; they can also introduce high residual stresses, which can be relieved by delamination and fracture. Tungsten films with high 1-2 GPa compressive residual stresses were sputter deposited on top of thin (below $100 \mathrm{~nm}$ ) copper and diamond-like carbon (DLC) films. Highly stressed films store large amounts of strain energy. When the strain energy release rate exceeds the films' interfacial toughness, delamination occurs. Compressive residual stresses cause film buckling and debonding, forming open channels. Profiles of the buckling delaminations were used to calculate the films' interfacial toughness and then were compared to the adhesion results obtained from the superlayer indentation test. Tests were conducted in both dry and wet environments and a significant drop in film adhesion, up to 100 times was noticed due to the presence of moisture at the film/substrate interface.
\end{abstract}

Keywords Thin films · Adhesion · Stress ·

Environmentally assisted fracture $\cdot$ Buckling

delamination - Telephone cord

\section{Introduction}

Thin films are used in a variety of applications, including information storage, optics, microelectronics and biomedical devices. These applications are possible

P.Waters $\cdot$ A.A.Volinsky $(\bowtie)$

Department of Mechanical Engineering,

University of South Florida,

4202 E Fowler Ave ENB118,

Tampa, FL 33620, USA

e-mail: volinsky@eng.usf.edu because of the films' magnetic, reflective, electrical, mechanical and other properties [1-6].

With the growing number of applications, there is an increase in the variety of operating environments thin films are exposed to. Normally well-adhered films are required, so the environmental effects on film adhesion need to be studied combined with the stress effects. Figure 1 presents a stress map obtained by the curvature method for a $1 \mu \mathrm{m}$ thick tungsten (W) film on a $<100>6$ " Si wafer. High variation of the residual stress is noticeable throughout the wafer. The bottom left corner has a $1 \mathrm{GPa}$ compressive residual stress, compared to an average of $500 \mathrm{MPa}$ observed elsewhere. Similar stress profiles for other thin films can be found in [7]. High compressive residual stress causes thin film buckling delamination, commonly called telephone cords, shown in Fig. 2 for the $1 \mu \mathrm{m}$ $\mathrm{W}$ film on top of a $20 \mathrm{~nm}$ diamond-like carbon (DLC) coating and in Fig. 3 for a polymer coating on $\mathrm{Al}$ substrate in a street sign.

Telephone cord delaminations have been observed in several film systems [8-12], including commercial semiconductor products [13], and appear to be the most common delamination pattern for thin films in compression. Buckling delamination appears to be a multiscale phenomenon; it can be induced by compressive stresses and moisture present at the film/ substrate interface, which significantly lowers thin film adhesion.

Here, the effect of moisture, which presence decreases film adhesion, was quantified for DLC and copper films. A 1- $\mu \mathrm{m}$ thick W superlayer with compressive residual stress was sputter deposited on top of the films in order to help induce their delamination from the substrate by means of nanoindentation [1]. 


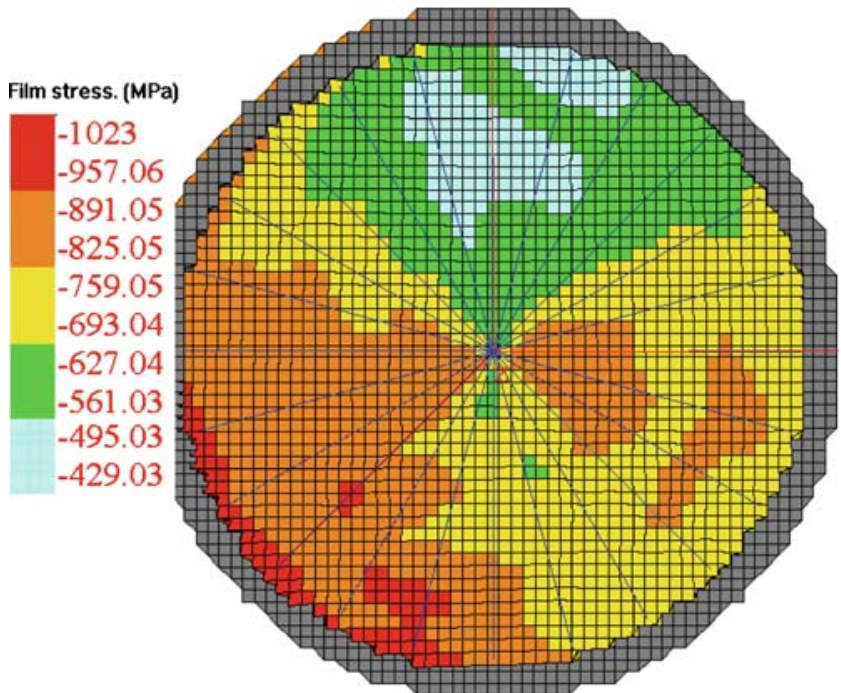

Fig. 1. Residual stress map of a $1 \mu \mathrm{m}$ thick sputter deposited TiW film on a Si $6 "$ wafer

Both the DLC and copper films were deposited on thermally oxidized $<100>\mathrm{Si}$ wafers. The initial motivation behind this research was to create a novel approach based on the superlayer indentation adhesion test [1] for measuring the effect of moisture on thin film adhesion. In the process of experimentation, it was discovered that the introduction of water to the DLC film/substrate interface causes delamination blisters to propagate across the wafer (Fig. 2). Crack propagation rates on the order of microns per second were observed. From the delamination profiles adhesion calculations were made and later compared with the superlayer indentation test results. This spontaneous delamination propagation caused by the introduction of water and residual stress relief is similar to the mechanically induced propagation of telephone cords caused by microprobe manipulation [8-10].

Moisture-induced telephone cord delamination propagation is a form of environmentally assisted fracture. Some common examples of this are seen in fading and delamination of vintage mirrors [14], and in buckling of polymer coatings on street signs undergoing daily and seasonal thermal cycling (Fig. 3). Other examples are delaminations and fading of telescope mirrors resulting in loss of reflectivity [15], as well as environmentally assisted fracture in recently developed silica-based low-k dielectric thin films [16].

\section{Theoretical Considerations}

Following Griffith's criterion a crack will continue to grow as long as the strain energy release rate $(G)$ from the surrounding strained material exceeds the energy per unit area required to form new surfaces [17]:

$G \geq \Gamma$

where $G$ is the strain energy release rate and $\Gamma$ is the material's resistance to crack propagation. The same concept can be applied for interfacial fracture in the case of a thin film delaminating from a substrate:

$G \geq \Gamma_{i}$

where $\Gamma_{i}$ is the interfacial toughness. The amount of stored elastic energy per unit area in a stressed thin film is:

$G=Z \frac{\sigma_{r}^{2} h}{E}$

where $Z$ is a geometric constant, ranging from 0.5 to 2 [18], which depends on the residual stress $\sigma_{r} ; h$ is the film thickness, and $E$ is the film's biaxial elastic modulus. This energy can be released by propagating a crack between the film and the substrate. If the interfacial toughness is reduced when water is introduced to the film/substrate interface, and the mechanical energy of the film remains the same, this could explain why crack propagation is observed leading to a release of large amounts of energy stored in the highly compressed tungsten superlayer.

Analysis of buckling delaminations was made by combining the Griffith criterion with the developments of Hutchinson and Suo [18], where the straight-sided blister was treated as a clamped Euler column. The column is described to have a width of $2 b$, the unbuckled film is subjected to uniform, equi-biaxial compressive in-plane stress and the film thickness, $h$, is

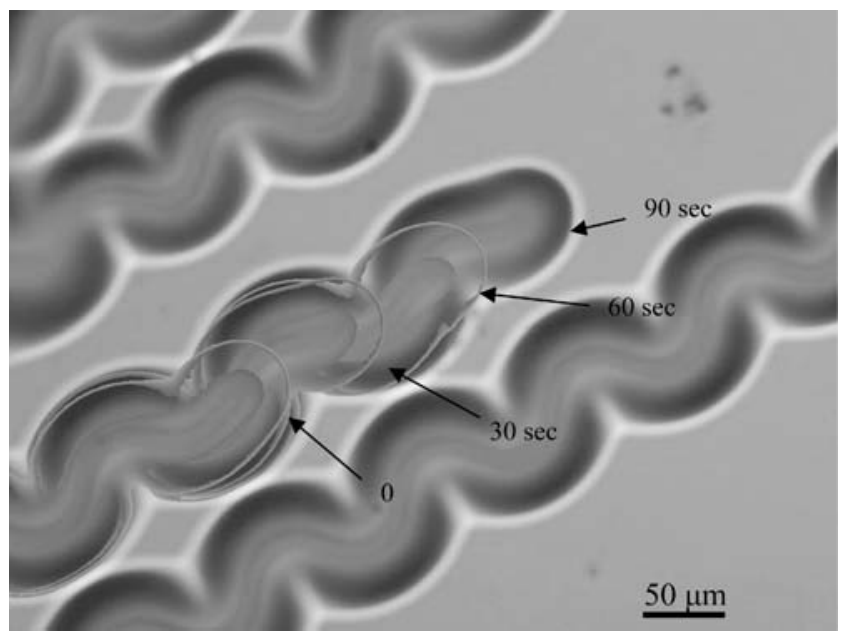

Fig. 2. Tungsten/DLC telephone cord delamination propagation at $2 \mu \mathrm{m} / \mathrm{s}$. Here, position of the delamination front is outlined as a function of time 
Fig. 3. (a) Polymer coating on $\mathrm{Al}$ substrate buckling delamination and fracture found in a street sign; (b) close-up of the upper left corner of (a)
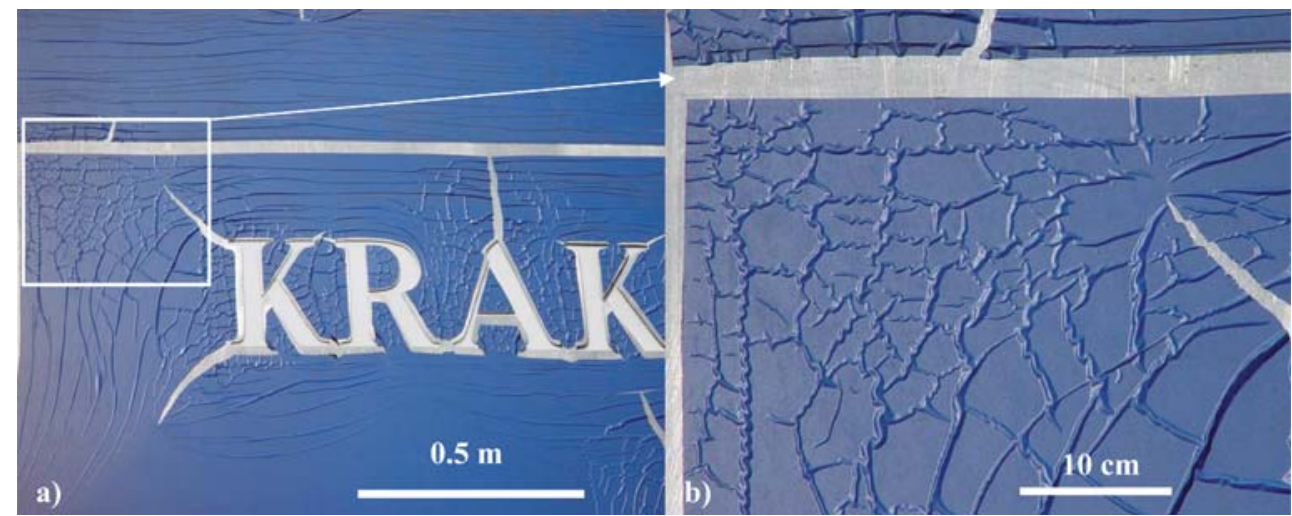

much less than the buckle half-width, $b$ (Fig. 4). The strain energy release rate of the straight-sided blisters can be calculated and equated with the film's adhesion in the case of buckling delamination. A Tencor P-20 profilometer was used to measure the width, $2 b$, and the height, $\delta$, of a straight-sided blister perpendicular to the direction of crack propagation (Fig. 5). These dimensions were then used to calculate the critical buckling stress and the residual stress [18]:

$\sigma_{B}=\frac{\pi^{2}}{12} \frac{E}{\left(1-v^{2}\right)}\left(\frac{h}{b}\right)^{2}$

$\sigma_{r}=\frac{3}{4} \sigma_{B}\left(\frac{\delta^{2}}{h^{2}}+1\right)$

Here, $E$ and $\nu$ are the elastic modulus and Poisson's ratio of the film; $b$ and $\delta$ are the blister half-width and height, respectively. Buckling stress of $275 \mathrm{MPa}$ and compressive residual stress of $1.9 \mathrm{GPa}$ was calculated for the W superlayer deposited on top of DLC films. With the buckling and residual stresses known the strain energy release rate perpendicular to the blister propagation direction is [18]:

$G(\Psi)=\frac{\left(1-v^{2}\right) h}{2 E}\left(\sigma_{r}-\sigma_{B}\right)\left(\sigma_{r}+3 \sigma_{B}\right)$

where $\Psi$ is the phase angle, which represents the mode mixity of an interfacial crack between dissimilar materials:

$\tan \Psi=\frac{K_{I I}}{K_{I}}=\frac{4 \cos \omega+\sqrt{3} \xi \sin \omega}{-4 \sin \omega+\sqrt{3} \xi \cos \omega}$

Here, $\xi$ equals $\delta / h$ and $\omega$ is a dimensionless function of the Dundurs' parameters, $\alpha$ and $\beta$, which describe the elastic mismatch between the film and the substrate [19].
The steady state strain energy release rate in the direction of blister propagation can be equated to the interfacial toughness as defined in [18]:

$G_{S S}=\frac{\left(1-v^{2}\right) h \sigma_{r}^{2}}{2 E}\left(1-\frac{\sigma_{B}}{\sigma_{r}}\right)^{2}$

The DLC film adhesion results from the straight-sided blister profiles were then compared to those obtained by the superlayer indentation test. Analysis for calculating the strain energy release rate by the superlayer indentation test is based on the work of Marshall and Evans [20], where the delamination blister is modeled as a rigidly clamped plate with further extension for multilayers by Kriese and Gerberich [21]:

$\begin{aligned} G= & \frac{h \sigma_{I}^{2}\left(1-v^{2}\right)}{2 E_{f}}+(1-\alpha) \frac{h \sigma_{R}^{2}(1-v)}{E_{f}} \\ & -(1-\alpha) \frac{h\left(\sigma_{I}-\sigma_{B}\right)^{2}(1-v)}{E_{f}}\end{aligned}$

$\alpha=1-\frac{1}{1+0.902(1-v)}$

where $\alpha$ represents the slope of the buckling load versus the edge displacement upon buckling ( $\alpha=1$ for the non-buckling case), and $\sigma_{I}$ is the stress induced by indentation. Biaxial stress $(\sigma)$-strain $(\varepsilon)$ relationship exists in this case:

$\sigma=\frac{\varepsilon E}{(1-v)}$

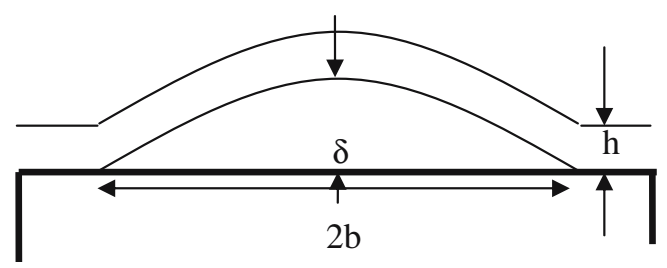

Fig. 4. Schematics of a straight-sided blister cross-section 
Fig. 5. (a) Straight and telephone cord blisters; (b) Delamination profiles

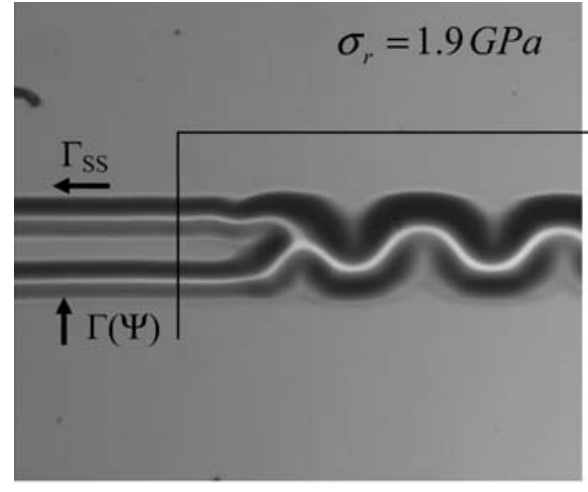

a)

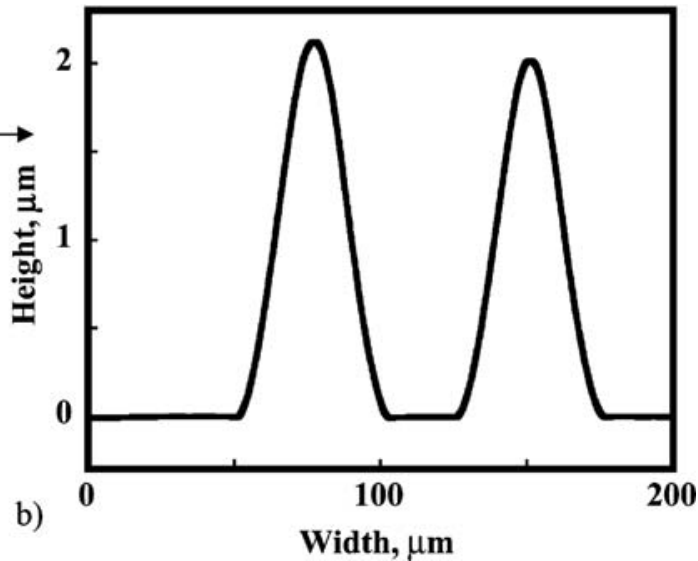

A multilayer analysis was used because of the addition of the tungsten superlayer on top of the copper and DLC films. After delaminations were observed, adhesive tape was applied to the samples and then peeled off to remove the delaminated film. EDX analysis was then performed to confirm that delamination was taking place at the $\mathrm{Cu} / \mathrm{Si}$ and DLC/Si interfaces and not at the $\mathrm{W} / \mathrm{Cu}$ and $\mathrm{W} / \mathrm{DLC}$ interfaces.

\section{Experimental Procedure}

The $20 \mathrm{~nm}$ thick DLC film (supplied by Seagate) was deposited by CVD on a $3^{\prime \prime}$ silicon $<100>$ wafer with a $300 \mathrm{~nm}$ thick layer of $\mathrm{SiO}_{2}$. An $800 \mathrm{~nm}$ thick tungsten superlayer (1.9 GPa compressive residual stress) was sputter deposited on top of the DLC film. Both of the 67 and $97 \mathrm{~nm}$ thick copper films were sputter deposited on $4^{\prime \prime}$ silicon $<100>$ wafers with $1 \mu$ m layers of $\mathrm{SiO}_{2}$. A $1.1-\mu \mathrm{m}$ thick tungsten superlayer was sputter deposited on top of both copper films (320 $\mathrm{MPa}$ compressive residual stress).

In order to induce film delamination propagation by the introduction of water, the DLC samples were mounted to a stage of an optical microscope with a small amount of adhesive. Since the samples were scribed-cut from a wafer, small blisters were randomly present at the sample edges. After an edge of the sample was located with blisters present, water was placed on the stage in contact with the sample edge. Delamination of W/DLC films was immediately seen when the water came into contact with the sample. Buckling delamination propagation continued until the water was taken away from the sample, or until the blister reached the film edge on the opposite side of the wafer $[10,11]$. The samples were then removed from the optical stage and blister dimensions were measured using a profilometer [Fig. 5(b)]. With the blister profile known the analysis in the previous section was used to calculate the DLC film adhesion.

Water-induced buckling delamination only occurred in DLC, and not in $\mathrm{Cu}$ films. The residual stress of 320 $\mathrm{MPa}$ present in the $\mathrm{W}$ superlayer of the $\mathrm{Cu}$ samples was too low to induce interfacial delamination. The superlayer residual stress was measured by the wafer curvature technique. Additional mechanical energy was required for delaminating the copper films. For this reason $\mathrm{Cu}$ film adhesion could only be measured using the superlayer indentation test.

The reasoning behind using the superlayer indentation test is that there are two problems likely to be encountered in a single layer indentation test: pile-up of the thin film around the indenter and penetration to depths greater than the film thickness. If the indent is made too deep, deformation and cracking of the substrate may occur, reducing the test validity. Both problems can be avoided by using the superlayer indentation technique. The superlayer can be deposited by means of sputtering, where the temperature is not high enough (below $100^{\circ} \mathrm{C}$ ) to alter the microstructure and the interfacial properties of the original film. The superlayer can be tailored to optimize

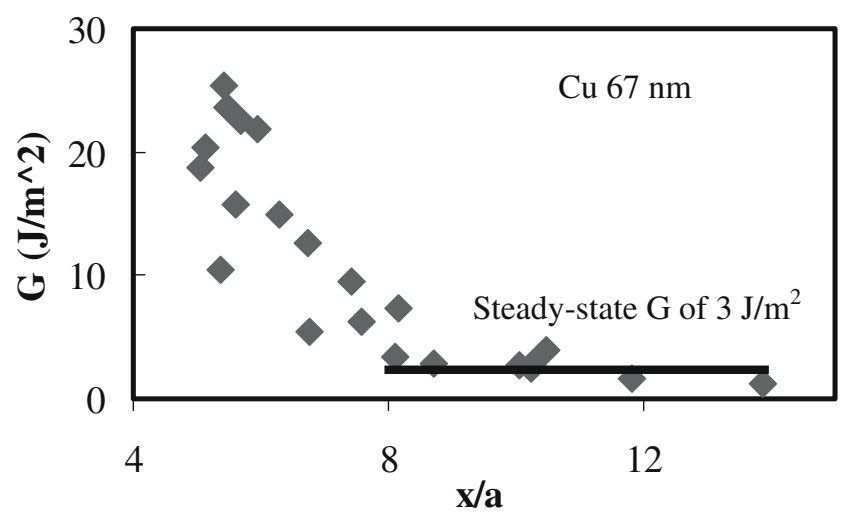

Fig. 6. Strain energy release rate for a $67 \mathrm{~nm} \mathrm{Cu}$ film as a function of blister to indentation radius ratio, $x / a$ 
Table 1 Dry vs. wet adhesion results

\begin{tabular}{lll}
\hline Sample & Blister diameter $(\mu \mathrm{m})$ & $\mathrm{G}\left(\mathrm{J} / \mathrm{m}^{2}\right)$ \\
\hline Cu 67 nm (Dry) & $20 \pm 5.0$ & $2.74 \pm 0.86$ \\
Cu 67 nm (Wet) & $150 \pm 15$ & $0.15 \pm 0.05$ \\
Cu 97 nm (Dry) & $20 \pm 5.0$ & $1.98 \pm 0.82$ \\
Cu 97 nm (Wet) & $150 \pm 20$ & $0.10 \pm 0.01$ \\
DLC (Dry) & $15 \pm 5.0$ & $3.0 \pm 0.31$ \\
DLC (Wet) & $100 \pm 20$ & $0.035 \pm 0.015$ \\
\hline
\end{tabular}

conditions for film thickness and residual stress, which allows for a greater delamination driving force for the same penetration depth to the film thickness ratio. One important condition that must be met for the superlayer indentation method to work is that the superlayer must adhere to the film stronger than the film adheres to the substrate. If this condition is not met, the adhesion measurement obtained will be for the superlayer to the film and not the adhesion of the film of interest to the substrate. The fracture path can usually be identified based on the substrate color upon removal of the delamination blisters with the adhesive tape. For the case where the superlayer is much thicker than the underlayer, the single layer analysis can still be applied as defined by Marshall and Evans [20].

In addition to knowing the sample geometry and the elastic properties of each layer, two physical measurements, namely the delamination blister radius and plastic indentation depth are required for calculating thin film adhesion. With the use of the Hysitron Triboindenter ${ }^{\circledR}$ the plastic indentation depth can be acquired from the Oliver-Pharr method by fitting a power law equation to the upper portion of the unloading curve [22]. The delamination blister radius can be measured with an optical microscope.

All samples were first tested in a dry environment, where three different trials of indents were made at different locations on the sample. Each trial consisted of ten indents in order to get good statistical variation and calculate an average adhesion value. This was necessary due to the local nature of the test and because the residual stress (Fig. 1) and the film thickness may vary across the sample. Indents were made to a range of maximum loads in order to obtain the steady state strain energy release rate value. The load range for indentation in the dry environment was kept between 100 and $250 \mathrm{mN}$. For indents made below a $100 \mathrm{mN}$ load, delamination blisters were small, almost indistinguishable in the optical microscope. For indents made to greater than a $250 \mathrm{mN}$ load, radial cracks in the buckled thin film and the substrate were present making adhesion measurements inaccurate. After several indents were performed, film adhesion was plotted against the delamination blister radius, $x$, to the indenter contact radius, $a$, ratio, (Fig. 6 ) in order to obtain a steady state energy release rate.

The contact radius is found by knowing the indenter tip geometry based on the indenter penetration depth, and the blister radius is measured optically using a microscope. For the indents performed in the dry environment the steady state strain energy release rate was observed for $x / a$ ratios greater than 8 . For smaller indents, where $x / a<5$, there is predominantly indentation-induced stress that drives interfacial delamination with a possible tip interaction effect in terms of the overlap of the indenter and the crack tip plastic zone sizes, leading to elevated adhesion values. For the $x / a$ ratios greater than 5, the crack growth, which approaches the steady state length, is primarily driven by the residual stress [23]. In Table 1 adhesion values reported for the dry environment are an average of the steady state strain energy release rates from the indents with the $x / a$ ratio between 8 and 12 (Fig. 6). A total of 30 indents were performed on each sample to provide an average film adhesion and one standard deviation.

For adhesion measurements in the wet environment using the superlayer indentation test an introductory indent was first performed to a depth just greater than the thickness of the W/Cu and W/DLC bi-layer and then the tip was unloaded. Water was introduced to the indentation with a syringe, followed by a second indent in the exact same location as the first one in order to further drive the crack propagation in the moist environment (Figs. 7 and 8). If the load of the second indent was too high, telephone cord and straight-sided delamination blisters could be observed emanating from the indent, invalidating the superlayer indentation test results. Before the double indent technique was applied in the wet environment it was first tried in the dry environment to test the technique validity [24]. Since the indenter records the first contact point as

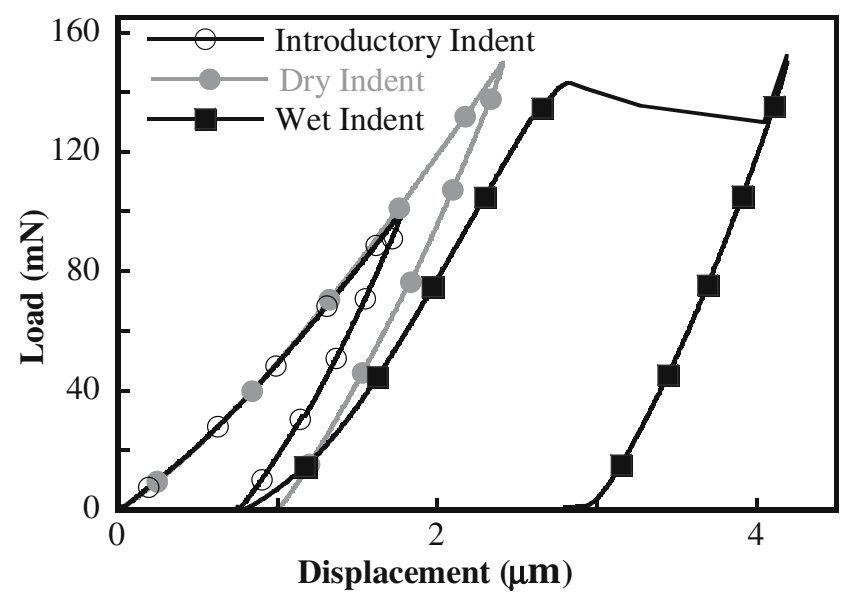

Fig. 7. Single vs. double indentation test 
Fig. 8. Comparison of dry and wet indent blisters
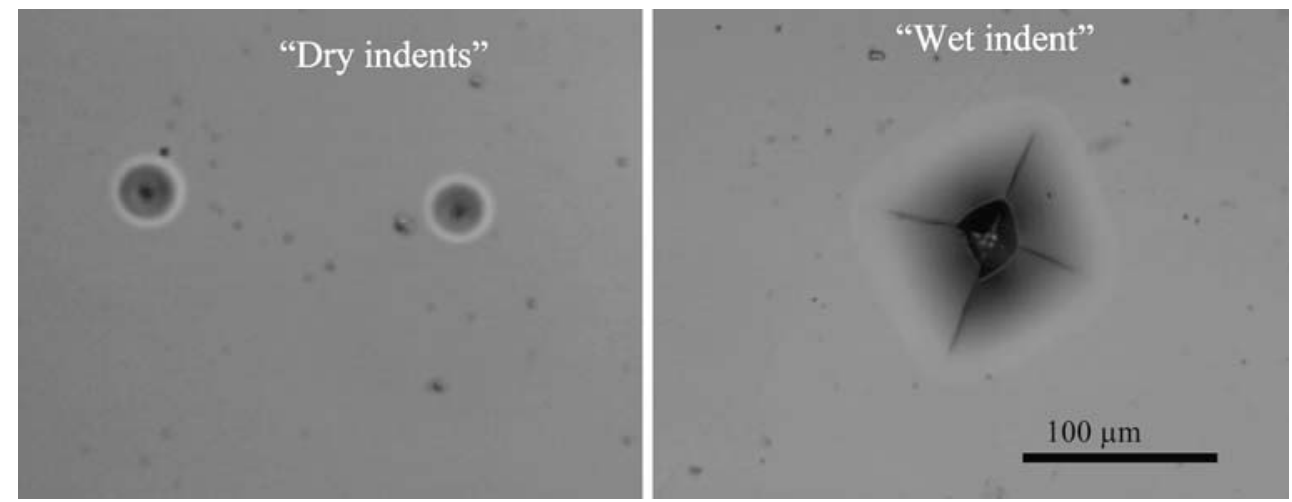

zero depth, the second indent (the "wet indent") contact depth had to be offset by the final depth of the introductory indent in order to obtain the final true indentation depth, as seen in Fig. 7.

\section{Results}

Using equation (4) the $\mathrm{W}$ superlayer buckling stress for the DLC sample was calculated to be $275 \mathrm{MPa}$ and this value along with the buckling profiles geometry from Fig. 5(b) were used with equation (5) to calculate the $\mathrm{W}$ residual stress of $1.9 \mathrm{GPa}$. This calculated value for the residual stress from buckling profiles agrees with the residual stress obtained by using the wafer curvature technique performed on the non-delaminated samples and with X-ray diffraction tests using the sine squared technique. The strain energy release rate for the DLC sample in the buckling direction, perpendicular to the blister propagation direction was calculated with equation (6) to be $6 \mathrm{~J} / \mathrm{m}^{2}$, and the steady state strain energy in the direction of blister propagation was calculated to be $3.6 \mathrm{~J} / \mathrm{m}^{2}$, using equation (8).

For indentation tests in the wet environment, the effect of moisture on thin film adhesion was only noticed when water was able to reach the film/substrate interface. If water was first placed on the surface of the film and then the film was indented, no changes in film adhesion were noticed with this procedure, similar to when the introductory indent in the double indentation test did not reach a depth equal to the film stack thickness. For indents performed in a wet environment with a deep enough introductory indent and with a second indent to the same maximum load as a single indent in a dry environment, larger delamination blister radii were immediately noticed. For example, both copper samples produced a blister diameter of approximately $20 \mu \mathrm{m}$ for a $150 \mathrm{mN}$ indent in the dry environment, which increased up to $150 \mu \mathrm{m}$ when the double indent was made in the wet environment to the same maximum load [23] (Fig. 8). For the tests in the wet environment the maximum load of the second indent had to be kept at a lower maximum than for the indents in the dry environment. The total indentation depth should not be too deep, otherwise penetrating the substrate causes extensive substrate fracture. Telephone cord delaminations were also induced in the DLC film if the second indent in the wet environment was too deep. The maximum load used for the wet indents was 150 $\mathrm{mN}$ compared to $250 \mathrm{mN}$ in the dry environment. It may be more feasible to perform depth-controlled indentations, opposite to load-controlled indentations, if equipment allows for it.

Adhesion measurements in the wet environment for the copper samples showed a reduction in adhesion by a factor of 10 to 20 compared to those performed in the dry environment. For the DLC films, a reduction in adhesion by a factor of 50 to 100 was observed when water was introduced at the film/substrate interface. Results for the two $\mathrm{Cu}$ samples and the DLC sample are shown in Table 1.

\section{Discussion}

Similar adhesion results were obtained from both the buckling profiles and the indentation tests. Analysis of the buckling profiles of straight-sided delamination blisters gave a steady-state adhesion value of $3.6 \mathrm{~J} / \mathrm{m}^{2}$ in the direction of blister propagation, comparable to the superlayer indentation test results of $3.0 \mathrm{~J} / \mathrm{m}^{2}$. One interesting observation made when inducing crack propagation with water is the mixture of both straight-sided and telephone cord delaminations in the W/DLC films. This is a result of the residual stress to the buckling stress ratio. Moon and colleagues have been able to control the buckling parameters by using lithographic techniques to create areas of low adhesion on substrates [25]. On a macroscopic level buckling patterns were controlled by gluing a polycarbonate 
strip to a PVC block and applying forces in two directions using screws (perpendicular and parallel to the strip) [26]. For both methods a residual to buckling stress ratio of $\sigma_{r} / \sigma_{B}=5$ produced straight-sided or Euler blisters, $\sigma_{r} / \sigma_{B}=6.5$ predicts bumps or varicose blisters and for $\sigma_{r} / \sigma_{B}=7.5$ telephone cord blisters would appear $[25,26]$. The $\sigma_{r} / \sigma_{B}$ ratio calculated for the DLC film was 6.9, which could explain why telephone cord delaminations were predominately observed, but straight-sided blisters could also be seen sometimes [Fig. 5(a)]. The mix of delamination types can be attributed to changes in the residual stress across the wafer.

The reduction in adhesion is primarily thought to be due to a chemical reaction at the crack tip which is assisting in bond rupture. Literature shows strong crack velocity dependence on relative humidity for ceramics, bulk glasses and metal/ $/ \mathrm{SiO}_{2}$ interfaces [27-30]. In those studies crack velocity was reported as a function of applied load in environments with varying relative humidity. Three distinct regions could be seen, where the first two depend on the reaction rate of water at the crack tip and the rate of water transport to the crack tip. The system used in this study is similar in terms of the increasingly applied load driving crack propagation, but the crack velocity was not measured during indentation. Water-induced telephone cord delamination propagation velocities showed high variability, ranging from 1 to 20 $\mu \mathrm{m} / \mathrm{s}$. For the indentation tests, instead of possible increased crack velocity, larger delamination blisters are observed. As the indenter tip is driven into the sample forcing film buckling and delamination from the substrate, water is provided a large enough channel to reach the crack tip. Along with indentation, capillary forces could be assisting in the transport of water to the crack tip.

Another significant effect of water reaching the interface could be due to lowering the surface energies of the newly formed surfaces at the crack tip $[14,23]$. Lower surface energies would result in a lowering of the true work of adhesion:

$$
W_{A}=\gamma_{f}+\gamma_{s}-\gamma_{f s}
$$

where $\gamma_{f}$ is the surface energy of film, $\gamma_{s}$ is the surface energy of the substrate and $\gamma_{f s}$ is the interfacial energy. This could be a reason for larger indentation blisters in the wet environment, as well as immediate delamination propagation for the W/DLC films induced by water.

\section{Conclusions}

It has been concluded that the Hutchinson-Suo and Marshall-Evans analysis for straight-sided and circular blisters give comparable results for thin film adhesion. For the two types of films tested the key to observing a reduction of film adhesion was that water must reach the interface between the film and the substrate. When water did reach the interface, copper film adhesion was reduced by 10 to 20 times, and DLC film adhesion was reduced by 50 to 100 times. Controlling residual stresses in thin films and keeping the interfaces free of moisture are the critical factors, especially when the application involves exposure to moist environments with externally applied stresses.

Acknowledgments The authors would like to acknowledge the financial support for this research from NACE International under contract N000140210024, and from NSF under contract DMI-0600231. DLC samples were prepared by Seagate Research. Consequent $\mathrm{W}$ deposition was performed at Washington State University in D. Bahr's group.

\section{References}

1. Volinsky AA, Moody NR, Gerberich WW (2002) Acta Mater 50:441-466.

2. Jeong H, Hata S, Shimokohbe A (2003) J MEMS 12:42-52.

3. Sun X, Jiang Z, Xin S, Yao Z (2005) Thin Solid Films 471:194-199.

4. Bryce R, Nguyen $H$, Nakeeran P, Clement T, Haugen C, Tykwinski R, DeCorby R, McMullin J (2004) Thin Solid Films 458:233-236.

5. Hsu TR (2002) MEMS and microsystems design and manufacture. McGraw-Hill, New York.

6. Ohring M (1992) The materials science of thin films. Academic, London.

7. Volinsky AA, Hauschildt M, Vella JB, Edwards NV, Gregory R, Gerberich WW (2002) Mater Res Soc Symp Proc 695:27-32.

8. Volinsky AA (2003) Mater Res Soc Symp Proc 749:W10.7.

9. Volinsky AA, Meyer DC, Leisegang T, Paufler P (2003) Mater Res Soc Symp Proc 795:U3.8.

10. Volinsky AA, Waters P, Wright G (2004) Mater Res Soc Symp Proc 855E:W3.16.

11. Volinsky AA, Waters P, Kiely JD, Johns E (2004) Mater Res Soc Symp Proc 854E:U9.5.

12. Volinsky AA, Moody NR, Meyer DC (2005) 11th International Congress on Fracture Proceedings. Turin, Italy.

13. Cotronakis J, Nilsson T (2003) International Conference on Compound Semiconductor Mfg., GaAsMANTECH, Inc. Conference Proceedings.

14. Volinsky AA, Waters P (2005) Tri-Service Conference on Corrosion, November 14-18, 2005, Orlando, Florida Proceedings Paper 06T104.

15. Burolla VP (1980) Sol Energy Mater 3:117-126.

16. Vlassak JJ, Lin Y, Tsui TY (2005) Mater Sci Eng A 391:159174.

17. Griffith AA (1920) Trans R Soc Lond 163-198.

18. Hutchinson JW, Suo Z (1992) Adv Appl Mech 29:63-191.

19. Dundurs J (1969) J Appl Mech 36:650-652. 
20. Marshall DB, Evans AG (1984) J Appl Phys 56:2632-2638.

21. Kriese MD, Gerberich WW, Moody NR (1999) J Mater Res 14:3007-3018.

22. Oliver WC, Pharr GM (1992) J Mater Res 7(6):1564-1580.

23. Volinsky AA, Tymiak N, Kriese MD, Gerberich WW (1999) Mater Res Soc Symp Proc 539:277-290.

24. Waters PJ, Volinsky AA (2005) Proceedings of IMECE: ASME, 2005 Nov. 5-11.
25. Moon M, Lee K, Oh K, Hutchinson JW (2004) Acta Mater 52(10):3151-3159.

26. Audoly B, Roman B, Pocheau A (2002) Eur Phys J B 27:7-10.

27. Wiederhorn SM (1967) J Am Ceram Soc 50(8):407-413.

28. Lawn BR (1975) J Mater Sci 10:469-480.

29. Cook RF, Liniger EG (1993) J Am Ceram Soc 5:1096-1105.

30. Lane MW, Snodgrass JM, Dauskardt RH (2001) Microelectron Reliab 41:1615-1624. 